\title{
PEMBERIAN POC MARTOB DALAM MENINGKATKAN PERTUMBUHAN DAN HASIL TANAMAN SAWI LADANG (Nasturtium montanum Wall.)
}

\author{
Herlina Kurniawati \\ Fakultas Pertanian Universitas Kapuas Sintang \\ Email: herlina_kurniawati@yahoo.com
}

\begin{abstract}
Abstrak: Sawi ladang cukup digemari oleh masyarakat di Kabupaten Sekadau namun kendalanya adalah produksi yang rendah, hal ini disebabkan karena kondisi tanah yang kurang subur serta rendah bahan organik. Oleh sebab itu agar produksi meningkat perlu pemberian pupuk organik dalam hal ini adalah POC Martob. Penelitian ini bertujuan untuk mengetahui Pengaruh pemberian POC Martob terhadap pertumbuhan dan hasil tanaman sawi ladang dan Dosis pemberian POC Martob yang memberikan pertumbuhan dan hasil tertinggi tanaman sawi ladang. Penelitian ini menggunakan metode eksperimen lapangan dan menggunakan rancangan lingkungan dengan pola Rancangan Acak Kelompok (RAK), faktor perlakuan dalam penelitian ini adalah POC Martob yang terdiri dari enam taraf, yaitu: $\mathrm{m}_{0}=$ tidak diberi POC Martob; $\mathrm{m}_{1}=1 \mathrm{ml}$ POC Martob per liter air; $\mathrm{m}_{2}=2 \mathrm{ml}$ POC Martob per liter air; $\mathrm{m}_{3}=3 \mathrm{ml}$ POC Martob per liter air; $\mathrm{m}_{4}=4 \mathrm{ml}$ POC Martob per liter air; $\mathrm{m}_{5}=5 \mathrm{ml}$ POC Martob per liter air. Data dianalisis dengan uji F dan dilanjutkan dengan uji BNJ pada selang kepercayaan 95\% dan 99\%. Hasil analisa data diketahui bahwa POC Martob berpengaruh terhadap pertumbuhan dan hasil tanaman sawi ladang. Pemberian $5 \mathrm{ml}$ POC Martob berpengaruh terhadap jumlah daun dan berat segar tanaman dengan jumlah daun rata-rata 8,44 helai daun dan berat segar rata-rata 200 gram per tanaman.
\end{abstract}

Kata Kunci : POC Martob, Sawi ladang, Pertumbuhan, Hasil

\section{PENDAHULUAN}

Mengembangkan tanaman sawi ladang di Kabupaten Sekadau sampai saat ini hanya bersifat musiman dan sedikit sekali yang berorientasi pada pasar. Sebagian besar masyarakat terutama petani padi lahan kering menanam sawi dilakukan setelah membakar ladang dan pengelolaannya juga tidak intensif serta hanya ditanam untuk konsumsi sehari-hari saja. Jika dilihat dari keadaan lahan atau sifat tanah tanaman sawi ladang masih dapat tumbuh pada tanah yang kurang subur seperti tanah PMK. Meskipun demikian agar diperoleh hasil yang optimal dan menguntungkan secara ekonomi, pengelolaan lahan yang baik perlu menjadi perhatian agar pertumbuhan dan perkembangan tanaman menjadi optimal. Salah satu cara mengelola lahan yang kurang subur seperti tanah PMK adalah dengan memberikan POC Martob.

Pengunaan POC Martob dapat dijadikan sebagai pengganti pupuk yang 
berbahan dasar kimia sintetik.

Penggunaan pupuk kimia sintetik dalam waktu berkepanjangan menimbulkan dampak negatif bagi lingkungan yang akan merusak struktur tanah serta dapat mencemari air dan menyebabkan terkikisnya bahan organik tanah. Salah satu upaya dalam mewujudkan konsep pertanian organik yang berkelanjutan adalah menggunakan pupuk organik salah satunya adalah POC Martob.

Menurut Scorpio Surabaya (2009), POC Martob mampu meningkatkan produksi tanaman serta tidak memberikan pengaruh negatif bagi kesehatan manusia karena bahan dasarnya terdiri dari bahan-bahan organik. Pemberian pupuk organik Martob dapat membantu bahan organik tanah yang rendah seperti pada tanah PMK karena tanah ini memiliki beberapa kelemahan diantaranya adalah rendahnya unsur hara serta tingginya timbunan $\mathrm{Al}$ dan Fe yang dapat meracuni tanaman serta menghambat penyerapan unsur tertentu yang sangat diperlukan oleh tanaman.

Tujuan penelitian ini untuk mengetahui: 1) Pengaruh pemberian POC Martob terhadap pertumbuhan dan hasil tanaman sawi ladang; 2) Dosis pemberian POC Martob yang memberikan pertumbuhan dan hasil tertinggi tanaman sawi ladang.

\section{METODOLOGI PENELITIAN}

\section{Metode Penelitian}

Penelitian ini menggunakan metode eksperimen lapangan dan menggunakan rancangan lingkungan dengan pola Rancangan Acak Kelompok (RAK), faktor perlakuan dalam penelitian ini adalah POC Martob yang terdiri dari enam taraf, seperti berikut: $\mathrm{m}_{0}=$ tidak diberi POC Martob;

$\mathrm{m}_{1}=1 \mathrm{ml}$ POC Martob per liter air; $\mathrm{m}_{2}=2 \mathrm{ml}$ POC Martob per liter air; $\mathrm{m}_{3}=3 \mathrm{ml}$ POC Martob per liter air; $\mathrm{m}_{4}=4 \mathrm{ml}$ POC Martob per liter air; $\mathrm{m}_{5}=5 \mathrm{ml}$ POC Martob per liter air. Satuan percobaan dalam penelitian ini terdiri dari 6 taraf POC Martob x 5 ulangan x 16 tanaman $=480$ tanaman percobaan. Satuan pengamatan pada penelitian ini diambil 4 tanaman dalam tiap petak perlakuan x 6 taraf POC Martob x 5 ulangan $=120$ tanaman pengamatan.

\section{Bahan dan Alat Penelitian}

Bahan percobaan terdiri dari: benih sawi ladang digunakan untuk bahan percobaan; POC Martob 
digunakan untuk perlakuan percobaan; pupuk kandang digunakan untuk mencampur media semai; papan, paku, kayu, dan spidol digunakan untuk membuat nama perlakuan.

Alat percobaan terdiri dari: parang dan cangkul digunakan untuk pembersihan dan pengolahan lahan; gergaji, palu, dan meteran digunakan untuk membuat papan perlakuan; gembor digunakan untuk menyiram tanaman; suntikan printer digunakan untuk menakar pupuk organic cair Martob.

\section{Waktu dan tempat penelitian}

Penelitian dilaksanakan di Desa Tapang Pulau Kecamatan Belitang Hilir Kabupaten Sekadau. Penelitian ini dimulai bulan Maret sampai Mei 2016.

\section{HASIL DAN PEMBAHASAN}

\section{Hasil Penelitian}

1. Jumlah Daun

Data hasil pengamatan dirata-ratakan dan kemudian dianalisis dengan sidik ragam. Hasil rerata pengamatan jumlah daun ditampilkan dalam Tabel 1. Rerata pengamatan jumlah daun selanjutnya dianalisi sidik ragam, seperti yang ditampilkan pada Tabel 2.

Tabel 1. Data Rerata Jumlah Daun

\begin{tabular}{cccccccc}
\hline \multirow{2}{*}{ Perlakuan } & \multicolumn{5}{c}{ Ulangan } & \multirow{2}{*}{ Jumlah } & \multirow{2}{*}{ Rerata } \\
\cline { 2 - 5 } & I & II & III & IV & V & & \\
\hline $\mathrm{m}_{0}$ & 5,00 & 6,00 & 5,75 & 5,00 & 5,00 & 26,75 & 5,44 \\
$\mathrm{~m}_{1}$ & 7,00 & 7,25 & 6,25 & 6,50 & 6,00 & 33,00 & 6,50 \\
$\mathrm{~m}_{2}$ & 6,50 & 6,75 & 6,50 & 6,50 & 6,75 & 33,00 & 6,63 \\
$\mathrm{~m}_{3}$ & 8,75 & 7,00 & 6,50 & 6,75 & 7,00 & 36,00 & 6,81 \\
$\mathrm{~m}_{4}$ & 7,75 & 7,50 & 7,75 & 6,00 & 7,25 & 36,25 & 7,13 \\
$\mathrm{~m}_{5}$ & 7,00 & 8,25 & 8,25 & 8,75 & 8,50 & 40,75 & 8,44 \\
\hline Total & $\mathbf{4 2 , 0 0}$ & $\mathbf{4 2 , 7 5}$ & $\mathbf{4 1 , 0 0}$ & $\mathbf{3 9 , 5 0}$ & $\mathbf{4 0 , 5 0}$ & $\mathbf{2 0 5 , 7 5}$ & $\mathbf{6 , 8 2}$ \\
\hline
\end{tabular}

Sumber: Pengamatan, 2016 
Tabel 2. Analisis Ragam Jumlah Daun

\begin{tabular}{lcccccc}
\hline \multicolumn{1}{c}{ SK } & DB & JK & KT & F Hit. & \multicolumn{2}{c}{ F Tabel } \\
\cline { 5 - 7 } & & & & & $\mathbf{0 . 0 5}$ & $\mathbf{0 . 0 1}$ \\
\hline Ulangan & 4 & 1,07 & 0,27 & $0,66^{\text {tn }}$ & 2,87 & 4,43 \\
Perlakuan & 5 & 21,74 & 4,35 & $10,67^{* *}$ & 2,71 & 4,10 \\
Galat & 20 & 8,15 & 0,41 & & & \\
\hline Total & $\mathbf{2 9}$ & $\mathbf{3 0 , 9 6}$ & & $\mathbf{k k}=\mathbf{9 , 3 6 \%}$ \\
\hline
\end{tabular}

Keterangan: $\mathrm{tn}=$ tidak berpengaruh nyata pada selang kepercayaan $5 \%$

$* *=$ berpengaruh sangat nyata pada selang kepercayaan $95 \%$

Hasil analisis ragam seperti yang tertera dalam Tabel 2 menunjukkan bahwa perlakuan POC Martob berpengaruh sangat nyata terhadap jumlah daun tanaman sawi ladang. Hasil dari Tabel 2 kemudian dilakukan uji lanjutan dengan uji Beda Nyata Jujur (BNJ) seperti yang terlihat dalam Tabel 3.

Tabel 3. Uji BNJ Pemberian POC Martob Terhadap Jumlah Daun

\begin{tabular}{|c|c|c|c|c|c|c|}
\hline Perlakuan & Rerata & & & Beda & & \\
\hline $\mathrm{m}_{0}$ & $5,44 \mathrm{a}$ & - & & & & \\
\hline $\mathrm{m}_{1}$ & $6,50 \mathrm{~b}$ & $1,06 * *$ & - & & & \\
\hline $\mathrm{m}_{2}$ & $6,63 \mathrm{bc}$ & $1,19 * *$ & $0,13^{\text {tn }}$ & - & & \\
\hline $\mathrm{m}_{3}$ & $6,81 \mathrm{bc}$ & $1,38 * *$ & $0,31^{\mathrm{tn}}$ & $0,19^{\text {tn }}$ & - & \\
\hline $\mathrm{m}_{4}$ & $7,13 \mathrm{c}$ & $1,69 * *$ & $0,63 *$ & $0,50^{\text {tn }}$ & $0,31^{\text {tn }}$ & - \\
\hline $\mathrm{m}_{5}$ & $8,44 \mathrm{~d}$ & $3,00 * *$ & $1,94 * *$ & $1,81 * *$ & $1,63 * *$ & $1,31 * *$ \\
\hline \multicolumn{7}{|c|}{$\mathrm{SE}=0,13$} \\
\hline \multicolumn{4}{|c|}{ Q $0.05=4,23$} & & \multicolumn{2}{|c|}{ BNJ $0.05=0,54$} \\
\hline \multicolumn{4}{|c|}{ Q $0.01=5,29$} & & \multicolumn{2}{|c|}{ BNJ $0.01=0,68$} \\
\hline
\end{tabular}

Sumber: pengamatan, 2016

Keterangan: tn = tidak beda nyata pada selang kepercayaan $95 \%$ $* *$ = beda nyata pada selang kepercayaan $99 \%$ 
Hasil uji BNJ menunjukkan bahwa pemberian $5 \mathrm{ml}$ POC Martob menghasilkan jumlah daun yang terbanyak, dengan selisih rata-rata 1,31 daun dengan tanaman yang diberi $4 \mathrm{ml}$, 1,63 daun dengan tanaman yang diberi 3 $\mathrm{ml}, 1,81$ daun dengan tanaman yang diberi $2 \mathrm{ml}, 1,94$ daun dengan tanaman yang diberi $1 \mathrm{ml}$, dan selisih 3,00 daun dengan tanaman yang tidak diberi POC Martob.

Tanaman yang diberi $4 \mathrm{ml}$ POC Martob tidak lebih banyak daunnya dibandingkan dengan tanaman yang diberi $3 \mathrm{ml}$ dan $2 \mathrm{ml}$ dengan selisih ratarata 0,31 dan 0,50 daun per tanaman.
Demikian juga dengan tanaman yang diberi $3 \mathrm{ml}$ dan $2 \mathrm{ml}$ tidak berbeda secara nyata jumlah daun yang dihasilkan dengan tanaman yang diberi $1 \mathrm{ml}$, selisih rata-rata adalah 0,19 dan 0,31 serta 0,13 daun pada tanaman yang diberi $2 \mathrm{ml}$ dengan tanaman yang diberi $1 \mathrm{ml}$. Tanaman yang diberi 3, 2, dan $1 \mathrm{ml}$ berbeda jumlah daun yang dihasilkan dibandingkan dengan tanaman yang tidak diberi POC Martob.

2. Berat Segar

$$
\text { Rata-rata hasil pengamatan }
$$
pengaruh pemberian POCMartob terhadap berat segar tanaman sawi ladang diperlihatkan dalam Tabel 4.

Tabel 4. Rerata Berat Segar Tanaman (g)

\begin{tabular}{|c|c|c|c|c|c|c|c|}
\hline \multirow{2}{*}{ Perlakuan } & \multicolumn{5}{|c|}{ Ulangan } & \multirow{2}{*}{ Jumlah } & \multirow{2}{*}{ Rerata } \\
\hline & $\mathbf{I}$ & II & III & IV & $\mathbf{V}$ & & \\
\hline $\mathrm{m}_{0}$ & 22,50 & 30,00 & 23,75 & 21,25 & 25,00 & 122,50 & 25,00 \\
\hline $\mathrm{m}_{1}$ & 32,50 & 32,50 & 35,00 & 33,75 & 37,50 & 171,25 & 34,69 \\
\hline $\mathrm{m}_{2}$ & 57,50 & 62,50 & 65,00 & 61,25 & 62,50 & 308,75 & 62,81 \\
\hline $\mathrm{m}_{3}$ & 115,00 & 125,00 & 120,00 & 112,50 & 150,00 & 622,50 & 126,88 \\
\hline $\mathrm{m}_{4}$ & 170,00 & 162,50 & 175,00 & 175,00 & 200,00 & 882,50 & 178,13 \\
\hline $\mathrm{m}_{5}$ & 195,00 & 200,00 & 187,50 & 200,00 & 212,50 & 995,00 & 200,00 \\
\hline Total & 592,50 & 612,50 & 606,25 & 603,75 & $\mathbf{6 8 7 , 5 0}$ & 3102,50 & 104,58 \\
\hline
\end{tabular}

Sumber: Pengamatan, 2016

Rerata hasil pengamatan seperti yang terlihat dalam Tabel 4 menunjukkan bahwa pemberian $5 \mathrm{ml}$ POC Martob menghasilkan berat segar rata-rata paling tinggi dibandingkan dengan pemberian $4 \mathrm{ml}, 3 \mathrm{ml}, 2 \mathrm{ml}, 1 \mathrm{ml}$ dan yang tidak diberi POC Martob. Hasil rerata dari pengamatan berat segar 
kemudian dianalisis sidik ragamnya dengan uji $\mathrm{F}$ seperti yang ditampilkan dalam Tabel 5.

Tabel 5. Analisis Ragam Berat Segar Tanaman (g)

\begin{tabular}{lcccccc}
\hline \multicolumn{1}{c}{ SK } & \multirow{2}{*}{ DB } & JK & KT & F Hit. & \multicolumn{2}{c}{ F Tabel } \\
\cline { 5 - 7 } & & & & & $\mathbf{0 . 0 5}$ & $\mathbf{0 . 0 1}$ \\
\hline Ulangan & 4 & 970,10 & 242,53 & $4,20^{*}$ & 2,87 & 4,43 \\
Perlakuan & 5 & 138349,17 & 27669,83 & $478,92^{* *}$ & 2,71 & 4,10 \\
Galat & 20 & 1155,52 & 57,78 & & & \\
\hline Total & $\mathbf{2 9}$ & $\mathbf{1 4 0 4 7 4 , 7 9}$ & & $\mathbf{k k}=\mathbf{7 , 2 7 \%}$ &
\end{tabular}

Keterangan: tn = tidak berpengaruh nyata pada selang kepercayaan 5\% $* *=$ berpengaruh sangat nyata pada selang kepercayaan $95 \%$

Hasil analisis ragam seperti yang ditampilkan dalam Tabel 5 menunjukkan bahwa POC Martob berpengaruh sangat nyata terhadap berat segar tanaman.
Agar diketahui perlakuan yang memberikan pengaruh sangat nyata terbaik dilakukan uji BNJ seperti disajikan dalam Tabel 6.

Tabel 6. Uji BNJ Pemberian POC Martob Terhadap Berat Segar (g)

\begin{tabular}{|c|c|c|c|c|c|c|}
\hline Perlakuan & Rerata & & & Beda & & \\
\hline $\mathrm{m}_{0}$ & $25,00 \mathrm{a}$ & - & & & & \\
\hline $\mathrm{m}_{1}$ & $34,69 \mathrm{~b}$ & $9,69 * *$ & - & & & \\
\hline $\mathrm{m}_{2}$ & $62,81 \mathrm{c}$ & $37,81 * *$ & $28,13 * *$ & - & & \\
\hline $\mathrm{m}_{3}$ & $126,88 \mathrm{~d}$ & $101,88 * *$ & $92,19 * *$ & $64,06 * *$ & - & \\
\hline $\mathrm{m}_{4}$ & $178,13 \mathrm{e}$ & $153,13 * *$ & $143,44 * *$ & $115,31 * *$ & $51,25 * *$ & - \\
\hline $\mathrm{m}_{5}$ & $200,00 \mathrm{f}$ & $175,00 * *$ & $165,31 * *$ & $137,19 * *$ & $73,13 * *$ & $21,88 * *$ \\
\hline \multicolumn{7}{|c|}{$\mathrm{SE}=1,52$} \\
\hline \multicolumn{5}{|c|}{ Q $0.05=4,23$} & \multicolumn{2}{|c|}{ BNJ $0.05=6,43$} \\
\hline \multicolumn{5}{|c|}{ Q $0.01=5,29$} & \multicolumn{2}{|c|}{ BNJ 0.01 = 8,04 } \\
\hline
\end{tabular}

Sumber: pengamatan, 2016

Keterangan: $* *$ = beda nyata pada selang kepercayaan $99 \%$ 
Hasil uji BNJ seperti yang terlihat pada Tabel 6 diketahui bahwa berat segar tanaman sawi ladang mengikuti taraf pemberian POC Martob, dimana semakin tinggi dosis yang diberikan juga disertai dengan berat segar tanaman yang semakin tinggi.

\section{Pembahasan}

Hasil analisis ragam menunjukkan bahwa pemberian POC Martob berpengaruh sangat nyata terhadap jumlah daun dan berat segar tanaman.

Hasil uji BNJ menunjukkan bahwa pemberian $5 \mathrm{ml}$ POC Martob menghasilkan jumlah daun yang terbanyak dibandingkan dengan pemberian 4, 3, 2, 1, dan $0 \mathrm{ml}$. Banyaknya jumlah daun karena pemberian $5 \mathrm{ml}$ POC Martob diduga berhubungan dengan semakin banyaknya jumlah unsur hara yang dapat disediakan dan diserap oleh tanaman sawi sebagai akibat semakin meningkatnya dosis POC Martob yang diberikan. Menurut Djumali dan Nurnasari (2012:1-20) bahwa dosis pupuk dengan kandungan unsur hara yang lengkap dapat mempengaruhi peubah fisiologi tanaman yang meliputi bondunaren blorofil doun hohot enacifil
No. 23 daun, laju fotosintesis, efisiensi cahaya mereduksi $\mathrm{CO} 2$, dan koefisien respirasi pemeliharaan daun.

Pemberian POC Martob pada dosis $4 \mathrm{ml}$ menunjukkan tidak adanya perbedaan jumlah daun yang nyata dibandingkan dengan tanaman yang diberi $3 \mathrm{ml}$, diduga pada taraf pemberian ini tanaman sawi ladang masih mengalami defisiensi (belum mencukupi) unsur hara sehingga sel-sel tanaman sawi dalam membentuk jaringan daun baru belum optimal. Hal yang serupa juga terjadi pada pemberian $3 \mathrm{ml}$ POC Martob, dimana daun yang dihasilkan oleh tanaman tidak berbeda nyata atau tidak lebih banyak dari daun tanaman yang diberi $2 \mathrm{ml}$ dan $1 \mathrm{ml}$. Menurut Aritonang dan Lasiwua (2011:47-54), pemberian pupuk yang tidak sesuai akan mempengaruhi pertumbuhan serta perkembangan tanaman, pemberian pupuk yang melebihi kebutuhan tanaman mengakibatkan tanaman mengalami penghamabatan pertumbuhan atau mengalami keracunan, sedangkan pemberian dibawah kebutuhan tanaman akan menyebabkan pengaruh yang tidak nyata terhadap pertumbuhan dan hasil tanaman.

Volume

12

Oktober 
Berat segar tanaman sawi ladang mengikuti taraf pemberian POC Martob, disebabkan oleh unsur-unsur N, P, dan K serta unsur-unsur lain yang terkandung di dalam POC Martob yang tersedia dan dapat diserap oleh tanaman sawi sehingga proses fotosintesis berjalan dengan lebih optimal dan fotosintat yang dihasilkan juga semakin meningkat. Hadisaputro, dkk., (2008:62-71) menyatakan bahwa pemberian pupuk $\mathrm{N}$ dan $\mathrm{K}$ dapat meningkatkan aktivitas PEP karboksilase pada daun, walaupun peran $\mathrm{N}$ dalam memacu aktivitas enzim fotosintesis ini lebih dominan dibanding dengan K. Selanjutnya Suwardi dan Efendi (2009:108-115) menyatakan bahwa unsur hara terutama $\mathrm{N}$ meningkatkan warna hijau daun, dan hal ini mempengaruhi peningkatan hasil tanaman.

Berat segar tanaman yang semakin tinggi mengikuti dosis pemberian POC Martob diduga karena peran unsur hara $\mathrm{N}, \mathrm{P}, \mathrm{K}$, serta unsur hara mikro yang terdapat di dalamnya sangat efektif dalam meningkatkan jumlah sel dalam jaringan tubuh tanaman sawi ladang, sehingga berpengaruh terhadap berat segar tanaman. Unsur P yang terkandung dalam POC Martob berperan penting dalam pembentukan dan pertumbuhan akar tanaman sawi, sehingga akar lebih mampu menyerap air dan unsur hara lebih banyak dan pada akhirnya secara keseluruhan tanaman akan tumbuh dan berkembang menjadi lebih.

Hal ini sejalan dengan hasil penelitian yang dilakukan oleh Pardosi, Irwanto, dan Mukhsin (2014:1-7), dalam proses fotosintesis unsur $\mathrm{P}$ juga berperan dalam pembentukan energi berupa ATP yang selanjutnya akan digunakan untuk translokasi fotosintat ke bagian organ tanaman yang membutuhkan. Selain itu peningkatan berat segar ini disebabkan adanya perbaikan pada sifat fisik dan kimia tanah oleh kerja POC, seperti efisiensi pupuk kimia, perbaikan aerasi tanah, peran humus dalam daya sangga dan peningkatan kapasitas tukar kation (KTK) tanah. Poerwowidodo (1992) menyatakan bahwa unsur hara makro dan unsur hara mikro yang terkandung dalam POC menghasilkan pengaruh yang komplek terhadap pembentukan dan produksi karbohidrat.

\section{KESIMPULAN DAN SARAN}

\section{Kesimpulan}

1. POC Martob berpengaruh terhadap pertumbuhan dan hasil tanaman sawi ladang. 
2. Pemberian $5 \mathrm{ml}$ POC Martob berpengaruh terhadap jumlah daun dan berat segar tanaman dengan jumlah daun rata-rata 8,44 helai daun dan berat segar rata-rata 200 gram per tanaman.

\section{Saran}

1. POC Martob dengan dosis $5 \mathrm{ml}$ per liter air dapat diberikan untuk meningkatkan pertumbuhan dan hasil tanaman sawi ladang.

2. Perlu dilakukan penelitian lanjutan menggunakan POC Martob dengan pemberian dosis yang lebih tinggi agar diketahui pertumbuhan dan hasil sawi ladang yang optima 


\section{DAFTAR PUSTAKA}

Aritonang AR, Lasiwua CD. 2011. Aplikasi POC Terhadap Pertumbuhan dan Produksi Tanaman Sawi. Jurnal Agrisistem 7(1): 47-54.

Djumali, Nurnasari E. 2012. Tanggapan Fisiologi Tanaman Tembakau Temanggung Terhadap Dosis Pupuk Nitrogen Serta Kaitannya Dengan Hasil dan Mutu Rajangan. Buletin Tanaman Tembakau, Serat dan Minyak Industri 4(1): 1-20.

Gaspersz, V. 1989. Metode Perancangan Percobaan. Bandung: Armico.

Hadisaputro S, Rochiman K, Mirzawan PDN, Sukarso G, dan Sugiharto B. 2008. Kajian Peran Hara Nitrogen dan Kalium Terhadap Aktivitas Phosphoenolpyruvate Carboxylase di dalam Daun Tebu Keprasan Varietas M 442-51 dan Ps 60. Jurnal Ilmu Dasar 9(1): 6271.

Lakitan, B. 1996. Fisiologi Pertumbuhan dan Perkembangan Tanaman. Jakarta: Raja Grafindo Perkasa.

Pardosi, AH., Irwanto., dan Mukhsin (2014). Respons Tanaman Sawi terhadap POC Limbah Sayuran pada Lahan Kering Ultisol. Prosiding Seminar Nasional Lahan Suboptimal 2014, Palembang 26-27 September 2014.

Poerwowidodo. 1992. Telaah Kesuburan Tanah. Bandung: Angkasa.

PT. Scorpio Surabaya. 2009. Pupuk Organik Martob. Surabaya: PT. Scorpio Surabaya.

Suwardi dan Effendi R. 2009. Efisiensi Penggunaan Pupuk N Pada Jagung Komposit Menggunakan Bagan Warna Daun. Prosiding Seminar Nasional Serealia, 108-115.

$\begin{array}{llllll}\text { 91PIPER } & \text { No. } & 23 & \text { Volume } & 12 & \text { Oktober }\end{array}$ 